E3S Web of Conferences 1, 06007 (2013)

DOI: $10.1051 / \mathrm{e} 3$ sconf/20130106007

(C) Owned by the authors, published by EDP Sciences, 2013

\title{
Natural background values for heavy metals in the sediments of a contaminated Northern Adriatic lagoon environment: a geochemical perspective
}

\author{
S. Covelli ${ }^{1}$, A. Emili ${ }^{1}$ and A. Acquavita ${ }^{2}$ \\ ${ }^{1}$ Dipartimento di Matematica \& Geoscienze, Università di Trieste, Via Weiss 2, 34128 Trieste, ITALY, covelli@units.it; \\ andemili@gmail.com \\ ${ }^{2}$ Osservatorio Alto Adriatico, Agenzia Regionale per la Protezione dell'Ambiente del Friuli Venezia Giulia \\ (ARPA-FVG), Via Cairoli 14, 33057, Palmanova, ITALY, acquavitaa@arpa.fvg.it mailto:soilchen@ntu.edu.tw
}

\begin{abstract}
Major and trace elements were determined in 14 sediment cores collected from the Marano and Grado Lagoon (northern Adriatic sea). The lagoon is contaminated by several harmful priority substances, heavy metals included, and it has also been declared a "polluted site of national interest" (SIN) mainly due to high $\mathrm{Hg}$ concentrations in sediments. Based on a normalization procedure involving predicted linear relationships for "metal vs Al" obtained from the core subsamples, background values for each metal were evaluated on a regional scale and according to the grain-size variability. Compared to Environmental Quality Standards reported in the Italian laws and regulations, the estimated background ranges show that bottom sediments are naturally "enriched" in some metals, such as $\mathrm{Cr}$, Ni and $\mathrm{Cd}$ especially in sediments with a high percentage of the fine component. A correct evaluation on sediment quality status should be made on the basis of regional background values for each metal, taking into account local geochemical characteristics, i.e. mineralogical composition and grain-size variability of sediments.
\end{abstract}

Key words: Heavy metals, normalization procedure, background, coastal sediments, Environmental Quality Standards

\section{Introduction}

The European Community Water Framework Directive (WFD 2000/60/EC) requires achievement of good ecological and chemical status both in waters and sediments of coastal and transitional water bodies by 2015. To this purpose, it establishes Environmental Quality Standards (EQS) for 33 priority substances, including some heavy metals ( $\mathrm{As}, \mathrm{Cd}, \mathrm{Cr}, \mathrm{Hg}, \mathrm{Ni}, \mathrm{Pb}$ ) of well recognized environmental importance and ecotoxicological effects. However, the use of these single EQS has the disadvantage of not taking into account the natural geochemical variability which is dependent on the sedimentary matrix. False anomalies may then arise because metal values tend to vary with mineralogy and grain-size, higher concentrations being associated with finer-grained sediments. Fine-grained sediments in particular show an ability to accumulate metals from atmospheric deposition, from soil erosion, or directly from wastewater discharge. Several procedures have been proposed for the normalization of geochemical data in river and marine sediments (Loring. 1991).
Normalization carried out using simple linear regression of metal content versus a grain-size proxy element has been demonstrated to be an useful approach in defining regional metal background values, taken into account local mineralogical characteristics and grain-size variability. On the basis of the geochemical data set of the Marano and Grado Lagoon, regional background values are proposed and compared to the EQS, taking into consideration the sediment grain size variability in the lagoon.

\section{Materials and Methods}

The Marano and Grado Lagoon (referred to simply as "Lagoon" hereafter) represents one of the best conserved wetlands in the whole Mediterranean area (Fig. 1A). The area hosts economic, tourism and industrial services, with fishing, clam harvesting and fish-farming. In spite of the level of protection, the Lagoon has also been declared a "polluted site of national interest" (SIN; Ministerial Decree 468/01) because of its high level of environmental risk. Among several contaminants, the 
Lagoon is one of the most $\mathrm{Hg}$ contaminated coastal zones in the Mediterranean, due to both industrial processes (chlor-alkali plant) and long-term mining activity. In the framework of the "MIRACLE" Project (Mercury Interdisciplinary Research for Appropriate Clam farming in Lagoon Environment), fourteen 1-m long sediment cores were collected in the subtidal and intertidal zones in summer 2008. Subsampling was performed by cutting 1-cm-thick slices. Analyses of total major ( $\mathrm{Al}$ and $\mathrm{Fe}$ ) and trace elements (As, $\mathrm{Cd}, \mathrm{Co}, \mathrm{Cr}, \mathrm{Cu}, \mathrm{Li}, \mathrm{Mn}, \mathrm{Ni}, \mathrm{Pb}$, $\mathrm{Sc}, \mathrm{V}, \mathrm{Zn}$ ) content were performed by ICP-OES after total digestion method ( $\mathrm{HF}+$ aqua regia) in a closed microwave system. $\mathrm{Hg}$ was analyzed through the CVAAS technique (Perkin Elmer AAnalyst 100-FIAS). Quality control was tested using certified reference materials (PACS-2 harbour sediment, NCR-CNR, Canada). Grain-size analysis was determined using a Malvern Mastersizer 2000 laser granulometer. Sedimentation rate assessments were also performed using ${ }^{210} \mathrm{~Pb}$ and ${ }^{137} \mathrm{Cs}$ radiodatings.

\section{Results and Discussion}

Only $\mathrm{Hg}$ profiles in all cores showed a typical anthropogenic trend of increasing metal concentration from the basal core sections, where local background values $\left(0.13 \pm 0.04 \mu \mathrm{g} \mathrm{g}^{-1}\right)$ were found, to the top core sections. The profiles clearly reflect the massive $\mathrm{Hg}$ contamination that has historically altered the study area, which has been well recorded into the lagoon sediments (Fig. 1B). Geochronological measurements showed that the depositional flux of $\mathrm{Hg}$ was influenced by anthropogenic inputs after 1800 , when cinnabar mining activity at Idrija (Slovenia) was more intense. After 1950, surface sediments were also affected by the discharge of the Aussa River, which delivers Hg from a chlor-alkali plant (Covelli et al., 2012). For other metals, concentration profiles are affected by grain-size variability and the anthropogenic component is not easily discernible by the lithogenic one. Data were then normalized by applying the procedure followed by Covelli and Fontolan (1996) and Covelli et al. (2006). By means of a data correlation matrix, the relationship between fine-grained fractions, possible grain-size proxy elements ( $\mathrm{Al}, \mathrm{Fe}, \mathrm{Li}$ and $\mathrm{Sc}$ ), and trace elements were examined. Aluminum showed the best correlation with the muddy fraction. The poor correlations between Al and $\mathrm{As}, \mathrm{Cd}$ and $\mathrm{Hg}$ suggest that their occurrence is not dependent on the muddy and/or aluminosilicate mineral fractions. Simple linear regressions versus Al were initially performed on all core levels and the results were plotted along with the $95 \%$ prediction limits (Fig. 1C).
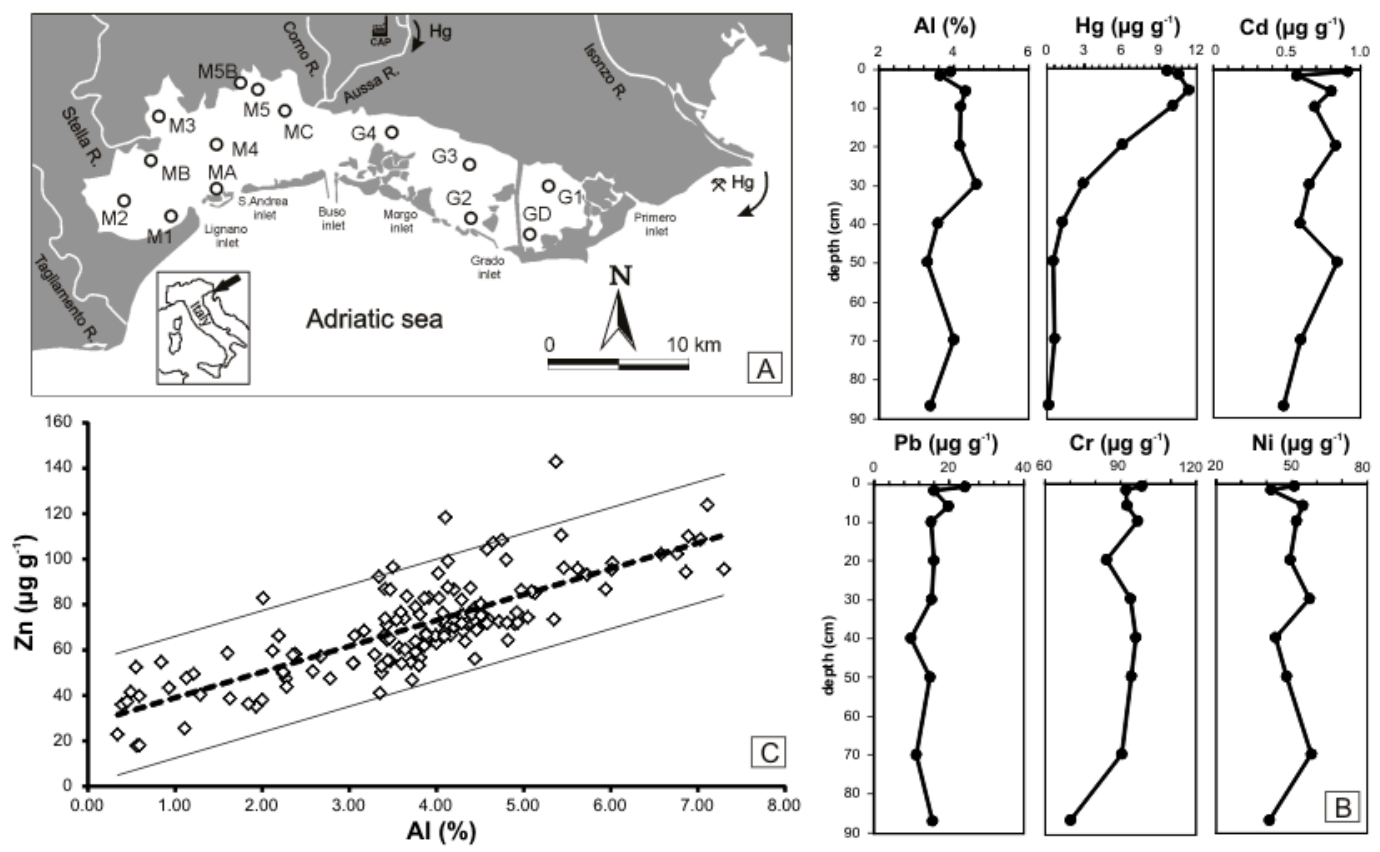

Fig. 1 - A) Sediment core sampling sites; B) example of metal profiles in a sediment core (G1); C) scatterplot with simple linear regression of $\mathrm{Zn}$ versus $\mathrm{Al}$ performed on all core levels plotted along with the $95 \%$ prediction limits.

Data points falling outside the two $95 \%$ predictions limits, delineating the expected natural range, were considered to be anomalous and removed from the original data set. Metal-Al linear relationships were recalculated for the samples statistically belonging to the natural population of lagoon sediments. These regression lines on a regional scale, along with prediction limits, can be used to assess the expected natural metal value in sediments, on the basis of the analyzed Al content in each sample. Since Al was well correlated with mud, the following step was to calculate the expected Al content range for the main textural classes (mud $<30 \%, 30-70 \%$ and $>70 \%$ ) of sediments. The final step was then to determine the expected metal concentration range for each textural class related to the muddy content. Mercury was the only element excluded from this procedure due to its high level of contamination (up to $12 \mu \mathrm{g} \mathrm{g}^{-1}$ ). If the expected concentrations of total metals in the Lagoon 
sediments are compared to the threshold values (EQS or environmental quality standard contents) reported in the Italian laws and regulations (Italian Environmental Ministry Decree no. 56/2009) for coastal sediments, As and $\mathrm{Pb}$ are always lower regardless of the textural class. Conversely, $\mathrm{Cr}$ and $\mathrm{Ni}$ exceed the threshold values in the Lagoon sediments only where the muddy component is higher than $30 \%$. This means that the Lagoon sediments are naturally "enriched" in $\mathrm{Cr}$ and Ni probably due to the sedimentary contribution from rivers which is supplied in terms of clay minerals, such as illite, kaolinite, and chlorite, and of chromite, a Cr-bearing spinel mineral, mainly originated from erosion of flysch outcropping in the surrounding area. On the other hand, $\mathrm{Cd}$ is always higher than EQS, regardless of the muddy content. It is hypothesized that other minerals such as sulphides (i.e. $\mathrm{ZnS}$ ) can be act as metal carriers in bottom sediments.

\section{Conclusion}

The approach followed in this study allowed to better define the lithogenic origin of some metals such as $\mathrm{Cr}, \mathrm{Ni}$ and $\mathrm{Cd}$, whose regional background values are higher than the EQS indicated by the national regulations on the subject, mostly the rules coming from the application of Water Framework Directive (WFD) EC 2000/60 (European Community, 2000). Besides, the results suggest that any consideration on sediment quality status on the basis of the total metal content cannot be limited only to the application of simple and general EQS. Regional background values for heavy metals should be determined for each coastal area considering sediment geochemical characteristics, i.e. mineralogical composition and grain-size variability. This approach also provides simple but useful information for studies on sediment quality assessment, also in connection with the management of dredged material in contaminated coastal environments.

\section{Acknowledgements}

This work was partially funded by the Commissario Delegato for the Marano and Grado Lagoon as a part of the "MIRACLE" Project (Mercury Interdisciplinary Research for Appropriate Clam farming in Lagoon Environment") in 2008-09.

\section{References}

Covelli S, Fontolan G. Application of a normalization procedure in determining regional geochemical baselines: Gulf of Trieste, Italy. Environ Geol 1996; 30: $34-45$.

Covelli S, Fontolan G, Faganeli J, Ogrinc N. Anthropogenic markers in the Holocene stratigraphic sequence of the Gulf of Trieste (northern Adriatic Sea). Mar Geol 2006; 230: 29-51.

Covelli S, Langone L, Acquavita A, Piani R, Emili A. Historical flux of mercury associated with mining and industrial sources in the Marano and Grado Lagoon (northern Adriatic sea). Est Coast \& Shelf Sci 2012, in press.

Loring DH. Normalization of heavy-metal data from estuarine and coastal sediments. ICES J Mar Sci 2001; 48: 101-115. 